\section{dettsomian iffectures}

\author{
ON
}

\section{MIDWIFERY AND DISEASES OF WOMEN.}

Delivered before the Medical Society of London.

$\mathrm{BY}$

C. H. F. ROUTH, M.D.,

PHYSICIAN TO THE SAMIRITAN hOSPITAL For WOMEN AND CHILDREN.

\section{LACTURE III.}

The Treatment of Fibrous Tumours.

Mr. President and Gristingex,-The treatment of uterine fibrous tumours forms the subject of our consideration to-night; and I shall speak, first, of the therapeutical measures which have been recommended; and, secondly, of the surgical appliances which have been found most efficacious.

I. Therapeutical Remedies. Several remelies have been recommended; but of these, the only three to which I shall refer are mercury, iodine (and its analogue bromine), and the liquor calcii chloridi.

From the time of $\mathrm{Sir}$ A. (Cooper down to the present day, the discutive properties of mercury have bcen well known in cases of internal enlargement, and especially in cases of uterine disease. Combined with local depletion, I know of no more efticient remedy in arrested involution of the impregnated uterus, and in hypertrophy of this organ. But I have seen some cases of uterine fibroid where I think the enlargement has diminished under its use. I do not say that it has entirely disappeared. In mere thickening and hypertrophy, it is without doubt very efficient.

On the use of iodine and iodide of potassium, the writings of Dr. Ashwell are so well known and explicit, that incidental allusion only is required. He gave iodine internally, and applied an iodine ointment locally to the cervix. The resolution was sometimes effected in from sixteen to eighteen weeks. This was especially the case with cervical tumours. In hard tumours of the walls, however, he admits that the remedy, as a discutient, was of no avail ; at most, it prevented only further increase. Dr. Simpson, on the other hand, recommends the bromide of potassium. In my hands, I must confess, that these remedies have not proved so useful as the bichloride of mercury.

More lately, Dr. M'Clintock has recommended the use of the liquor calcii chloridi (Dublin Pharmacopria); but I have no experience in its use. In one case only, I gave it to the extent of eighty drops three times a day for four months. It seemed to give the patient comfort, and a slight relief to her symptoms; but the tumour did not become sensibly smaller.

The absorption, however, of fibroids which are imbedded in the uterine walls, is precisely that which we have been chiefly discussing; and these tumours are exactly those upon which those remedies are least operative.

Hamorrhage. The symptom which seems to give rise to the greatest inconvenience in these cases, and calls most for treatment, is hæmorrhage. If this depend on hepatic congestion, or be accompanied with it, I believe no remedy is so efficient as mercury. In these cases, also, oxide of silver, in doses of one to three grains with half a grain of extract of Indian hemp, has often acted very decidedly; although, in someinstances, theoxide of silver has appeared to purge. In other instances, no such operation has been observed; but the hæmorrhage has ceased. Sulphuric acid and gallic acid, also, as most of us have doubtless observed, are powerful remedies in arresting the hæmorrhage. Without doubt, however, turpentine is the surest remedy, if the patient's stomach can bear it. Better still is a mixture of dilute sulphuric acid and turpentine; but the women that can bear to take this atrocious compound are very few and far between. 'Ten minims of oil of turpentine in a mixture three times a day has sufficed to arrest the flow of blood in two or three days. Sometimes, however, all these remedies fail; and more energetic measures are demanded, and these are chiefly local in character.

There are three ways in which, locally or by manual operation, the hæmorrhage may be arrested-at least, for the time. These are: 1, injection; 2, cutting open the internal os; 3 , directly cutting upon that part of the mucous membrane which covers the fibroid projecting into the uterine cavity. I do not, of course, allude here to polypi.

1. Injections. It is unnecessary that I should refer to this method of arrest at present, as I have already published my views. on this subject at length, in a paper which you may all read, in the Obstetrical Transactions. I will only add a few words, in justice to a colleague of mine, Dr. Savage, whose name, although I gave him due credit in that paper for the discovery, has been overlooked. 'The scraping of the uterus by an uterine gouge was a French innovation. 'The injection with tincture of iodine, after dilatation by a sponge-tent, was Dr. Savage's discovery. The previous dilatation allows the escape of the fluid subsequently injected; and then those acute pains, which occasionally determine peritonitis when the uterus is injected without previous dilatation, are avoided. Dr. Savage prefers to inject iodine; that is, the strong Edinburgh solution undiluted. I like the tincture of sesquichloride of iron. I have never known an instance where, under this treatment, the hæmorrhage has not ceased for the time; I mean in fibroids. Of course, in ordinary cases of menorrhagia, the result is permanent.

I may mention two cases of fibroid tumour. One was a patient of Dr. Savage's, whom he transferred to me. She had an enormous uterine fibroid. At every monthly period the catamenial flow was profuse. The plan adopted was to inject the cavity, after dilatation by a sponge-tent, after the first or second day of the flow. It was always arrested, and never recurred till the next period, when it was again arrested in the same manner. The patient had time thus to rally and gain strength, and left the hospital much relieved.

The other case was remarkable in more ways than one. It was a case of fibroid and cancer combined, occurring in a young woman aged about 28 . She came into the hospital completely exsanguine-with all the marked uncomfortable symptoms of anæmia. The tumour was very large, and extended above the umbilicus. The hæmorrhage was copious, amounting to 
flooding at every period. The odour of the blood was in no way cancerous. This patient had sponge-tents first used; and in the exploration by the index finger, these fungoid growths here shewn were made out, but supposed to be merely mucous polypi. Portions of these were scraped away by the gouge, and she was consequently injected with tincture of sesquichloride of iron. The hæmorrhage was arrested instantaneously; and it was quite pleasant to see how the patient rallied during the month, getting flesh and colour and walking about, in fact, able once more to enjoy life. This treatment was repeated three or four times, and she was greatly better. A fifth time the menstrual period recurred; and $I$ was thinking of injecting her the next day. On my arrival, I found her in a state of high fever, with abdominal tenderness. It proved to be acute peritonitis. It was fortunate for me, that I had not injected her now, else I should have concluded that the peritonitis had been due to the injection. The post mortem examination revealed the state of things you see represented in this drawing. The tumour was fibrous, with cancerous masses here and there.

2. Another means of arresting the hæmorrhage is by incising the os. I do not stop here to inquire as to who was the discoverer of this mode of procedure, and as to whether the merit is to be claimed by America, England, Ireland, or France. Of its practical value, I am convinced. It is a plan we have carried on at least for two years at the Samaritan Hospital. I explained the modus operandi of this incision in my second lecture.

3. Equally effective is Dr. Atlee's plan of incising the mucous membrane over a tumour projecting into the cavity. 'To the modus operandi in this case, I also referred in my previous lectures; and, therefore, I need not detain you any longer upon this point.

Treatment by Electricity. It is now many years since I was consulted by a lady for what appeared to be a fibrous growth of the breast.

It was a large tumour, of about the size of a turkey's egg, very hard, resistant, and producing some sickness on pressure. It gave rise to considerable anxiety at the time; more especially as the mother had just died of cancer, and an aunt had also succumbed to the same affection. Reflecting on the fact that, if in an ordinary galvanic battery a quantity of fresh meat is placed in connection with the positive pole, this rapidly putrefies, and believing that this fact, which I noticed years ago, was explanatory of the putrefaction of meat even in very cold countries at periods when the atmosphere is surcharged with positive electricity; it occurred to me that, if I could place this tumour in the same position, I should lead to its oxidation or decomposition, and so cure my patient. I did so. A zinc plate was moulded to the affected breast; a copper one to the healthy one. Interposed between the breast and plate, in both cases, was a piece of calico dipped in vinegar. In six weeks the cure was complete.

I was not so successful in a case of fibro-cystic disease. IIere the disease made its progress apparently unaffected, and 1 was compelled at last to amputate the breast. 'The disease was radically cured.

Another case in which I tried electricity was one of fibroid of the uterus. C. B., aged 44, was admitted under my care, at first for a few days, subsequently for a longer period. (My notes of her case on first admission are meagre.) The patient was a rickety diminutive subject. She had been married nineteen years, but was childless. She had been usually regular till within the last twelve months, since which period she had suffered from dysmenorrhoa, and the catamenia had occurred only three times. Then they were copious, lasting four or five days, being very dark and clotty. 'They last appeared three weeks before admission. She first noticed the tumour eighteen months previously, in the iliac region of the right side. This was free from pain. She now complained of a great deal of pelvic pain and discomfort, and her motions were with difficulty passed. On vaginal examination, the os was found to be small, and the cervix prolonged. On the right side, in the position of the ovary, but lower down, was a hard tumour, which pushed the womb to the left side, and was seemingly attached to it, moving the latter slightly when moved itself. The movement, however, in the tumour itself, was limited. It filled the entire pelvic cavity, and extended above the pelvis. Pressure made above was felt in the vagina on the finger. The tumour was intensely hard except at one point. Here it was doubtful if there were not obscure fluctuation.

She was re-admitted December 11th, 1853 . Since her former admission, the patient had been taking bichloride of mercury, except for about a month when she caught cold. The following points were now made out. The sound penetrated only three-fourths of an inch. Two tumours could now be felt in the abdomen; one to the left side and towards the median line, and projecting about an inch above the pubes the other tumour, much larger and thicker, projecting two or three inches above the pubes, and placed more towards the right side. Pressure from above was responded upon the index finger in the vagina. The pelvis, as before, was occupied by a large tumour, which seemed to be made up of the entire uterus uniformly enlarged. The os was very small, looking backwards and downwards.

An attempt was made to dilate the os by spongetents. This failed. Subsequently, assisted by my friend Dr. Althaus, I passed a strong electrical current of high intensity through the tumour, placing as the positive pole an iron sound covered with gutta percha except at its distal end within the os as far as it could go; and the negative pole at the back opposite the sacrum. This was continued unremittingly for two hours. The effect was to cause the os to dilate a very little. It gave rise to a great deal of pain in the back, described by her as that of a large pin sticking into her. This was at once relieved on disconnecting the pole. This treatment was persisted in for four days. No greater effect upon the os was produced. The electricity seemed to give her pain subsequently to its removal. The catamenia appeared on January 1st, when the treatment was suspended, to be resumed again on the 4th. No effect appeared to have been produced upon the tumour by the electricity up to the $17 \mathrm{th}$, when she left the hospital. An ulcerated spot had appeared on the back; no doubt, induced by the current; and a similar spot upon the os uteri and part of the cervix. This was more to be regretted, as the latter gave rise to as severe a gonorrhœa in the husband as I ever saw. In the long run, however, it seemed to do good. The tumour, in the course of a year, was become about as small as the fist, and all unpleasant sensations in connection with it had disappeared. I have seen this patient lately. The tumour is not now to be felt

'The employment of electricity to act upon fibroids is comparatively new. In future experiments, I purpose applying it by means of wires in the centre of the tumour: in this way, destroying and solidifying all the blood about the needles, without contact with the external air. I hope I may thus succed in ex- 
citing in it the process of absorption. The following remarks by Dr. Althaus are interesting, as exemplifying the absorptive action of electricity in cases of grlandular tumours.

"Faradisation and galvanisation may be usefully employed for certain tumours, especially of the glandular kind, and some forms of struma; and are chiefly to be recommended where surgical operations are impracticable, on account of the seat of the tumour, or where the patient is averse to such operations. A striking case of this kind occurred a short time ago in the practice of Professor Langenbeck and Dr. Meyer of Berlin. The patient suffered from a hard glandular tumour, as large as the head of an adult, and lodged between the head and the right shoulder, filling up the space between the lower jaw, the mastoid process, and the linea semicircularis inferior of the occipital bone, and extending backwards in the direction of the vertebral column, which was dislodged towards the left side. The circumference of the left side of the neck was only six inches, while that of the right side was no less than fourteen. After fifty-six applications of the induced current, the tumour was reduced to one-half of its previous size, and by further treatment its bulk was still more diminished. In such cases, each operation should last for about an hour, and the treatment must be persevered in for a considerable time if beneficial results are to be obtained. Galvanisation seems, in the treatment of these affections, equally valuable as Faradisation."

[To be continued.]

\section{Illustrations}

\section{or \\ HOSPITAL PRACTICE: METROPOLITAN AND PROVINCIAL.}

ROYAL ALBERT HOSPITAL, DEVONPORT. COMPOUND HYDATID CYSTS OF LIVER: PERFORATION OF DIAPHRAGM.

Reported by Vivian Wearne, Esq., House-Surgeon. Charles $\Lambda$., aged 49, a mason, was brought in dead on January 26th, 1864. The history of the case was that, after ascending a ladder with a hod of mortar on bis back, he stumbled forward on reaching the scaffold, and expired immediately. Previously, he had made no complaints of being in ill health. He had been a temperate man, and enjoyed good health.

Autopsy forty-eight hours after death. The body was in good condition. The brain was congested, but normal. The heart was flabby; there was slight thickening of the mitral valves. The lungs were intensely congested, but swam in water. On the right side, the diaphragm encroached on the cavity of the thorax, extending as high as the fourth rib; on the left side, as high as the fifth rib. A white albuminoid substance was adherent to the thoracic surface of the diaphragm. On removing it, some jelly-like matter, followed by some small hydatid cysts, exuded through a perforation of the diaphragm. The liver was adherent to the diaphragm, stomach, duodenum, and vertebral column : it was very friable. The left lobe was occupied and replaced by a large eollection of hydatid cysts. One large compound hydatid cyst, of about the size of a child's head, had its base of attachment from the right lobe; on its under surface was a thin layer of liver-substance, about a quarter of an inch in thickness; this was the only remains of the left lobe. This cyst was filled with hydatid cysts and shrivelled hydatids. These secondary cysts, over two hundred in number, varied in size from that of a hen's egg to that of a pea. There were other large primary cysts; one, about the size of an orange, contained a clear fluid, with many hydatids in the fluid; another one contained only shrivelled hydatids. The whole formed a huge mass, and had formed adhesions to, and afterwards perforated, the diaphragm. The kidneys were healthy. 'The stomach was loaded with the contents of a recent meal, of healthy structure; it was adherent to the liver.

I would only remark on the slight derangement to the general health, from a disease which must have had its origin at some distant period. The congestion of the lungs was the immediate cause of death; whether it was caused by the perforation of the diaphragm, or by active exertion after a hearty meal by a man with a feeble heart, could not be ascertained.

\section{Gitiginal Communitatíns.}

\section{" "IIS SIX'LY YEARS SINCE." DR. GEORGE FORDYCE.}

By Thomas Martin, Esq., Reigate.

IT is generally admitted that biography is one of the most pleasing and interesting, and perhaps one of the most useful, departments of our literature; and medical biography must be more especially so to members of the profession.

In the obituary of the Gentleman's Magazine for 1802 (p. 508) is a memoir of Dr. George Fordyce ; and there is also an article in Dr. Aikin's Biography (vol. iv, p. 162) on the same eminent physician, medical writer, and lecturer. Either or both of these memoirs are sufficiently full and ample for the general reader; but the profession may have no objection to something more; and I am enabled, from personal knowledge of Dr. Fordyce as his pupil, to offer my recollections of additional facts and circumstances respecting him to the readers of this JournaL, in the following statement.

On the 1st of October, 1796, I attended the introductory lecture of Mr. Cline at St. Thomas's Hospital. There was a well filled theatre. The lecture was delivered with a calm dignity in appropriate and impressive language, and was listened to with deep and silent attention by all who were present; and at the conclusion there were no noisy demonstrations of applause, often so inconsistent with propriety and good taste. Mr. Cline was always listened to with profound attention by all who were present; and, at the conclusion of each session, his valedictory address to those students who were about to leave the school would produce even tears from some who heard him; but it never occurred to the students of that day audibly to applaud a medical or a scientific lecturer.

It was determined that my school should be that of the then united hospitals. I must, therefore, have a lodging near at hand; and I took rooms at 22, St. Saviour's Church Yard, next door to Dr. Haighton's 